\title{
MODELING OF THE KINETIC OF SALICYLIC ACID ADSORPTION IN POLYMERIC AND ACTIVATED CHARCOAL ADSORBENTS
}

\author{
L.D.T. Câmara a, \\ A. J. Silva Neto ${ }^{b}$, \\ ${ }^{\text {a, b }}$ Instituto Politécnico da Universidade do \\ Estado do Rio de Janeiro (IPRJ-UERJ), \\ Departamento de Engenharia Mecânica e \\ Energia-DEMEC \\ P.O. Box 97282, CEP 28601-970 \\ Nova Friburgo-RJ, Brazil. \\ adcamara@iprj.uerj.br , ${ }^{\mathrm{b}}$ ajsneto@iprj.uerj.br
}

\section{ABSTRACT}

The understanding of adsorption mechanisms of compounds utilized in many medications and prescription drugs represents an important step for the development of different separation processes of such substances. The adsorption kinetic study of such chemical compounds through the application of new models permits a better comprehension of the involved mechanisms, leading to the estimation of important parameters that will be incorporated in the equipment design. In this work a kinetic model of irreversible adsorption is implemented, which is dependent on both solute and site concentrations. It showed to be very effective correlating the simulated results with the adsorption experiments of salicylic acid through three adsorbents in different temperature conditions. The application of an inverse problem approach, with the minimization of the squared residues cost function, was successful in determining the kinetic parameters. The increase in the kinetic constants obtained with the temperature increase was followed by a reduction in the adsorption capacity of the adsorbents. Thermodynamic parameters were also estimated, leading to the comprehension about the equilibrium states of the adsorption systems considered.

Keywords: Kinetic modeling, Inverse Problem, Salicylic acid, Thermodynamic Analysis

\section{NOMENCLATURE}

$k_{i} \quad$ Kinetic constant

$r_{i} \quad$ Consumption rate of solute $\mathrm{i}$

$V \quad$ Tank volume

$n_{j} \quad$ Moles number of compound $\mathrm{j}$

$C_{t} \quad$ Total site concentration

$C_{s} \quad$ Vacant site concentration

$C_{A s} \quad$ Occupied site concentration

$C_{A} \quad$ Solute concentration

$C_{A 0} \quad$ Initial solute concentration

$C_{e q} \quad$ Equilibrium solute concentration

$C_{\text {exp }} \quad$ Experimental concentration

$C_{c a l} \quad$ Calculated concentration

$N \quad$ Total number of experimental points

A Ahrrenius frequency factor

$E_{a} \quad$ Activation energy

$R \quad$ Universal constant

$T$ Temperature

$G \quad$ Free energy of Gibbs

$H \quad$ Enthalpy

$S \quad$ Entropy

$K_{c} \quad$ Equilibrium constant

\section{INTRODUCTION}

The comprehension about the adsorption mechanisms of chemical compounds utilized in medicines is an important step for the development and improvement of several adsorption processes evolved with such substances, such as separation, purification, decontamination of wastewaters etc.

The agitated batch process of adsorption is an important method used for equilibrium parameters estimation, which are applied in the processes modeling such as chromatography and simulated moving bed (SMB) separation. The hydrodynamic aspects of these processes become the kinetic modeling an interesting tool for the process modeling in obtaining parameters that will be incorporated in the equipment design.

The application of an inverse problem methodology for chromatographic systems is a new promising area since the solution of inverse problems has several relevant applications in the engineering field (Vasconcellos et al., 2003). Other results can be found in Vasconcellos et al. (2002a, 2002b), Lugon et al. (2001), Denisov (2000), Felinger at al., (2003), and Folly et al. (2005). In the work of Vasconcellos et al. (2003) the inverse problem formulation with the minimization of a cost function of squared residues was applied in the mass transfer parameters estimation of protein adsorption (Bovine serum albumin-BSA). The optimization method utilized is the same applied by Folly et al. (2005), the 
Levenberg-Marquardt. The method in both applications was successful in determining the parameters of non-linear equations.

Some contributions in the application of adsorption kinetic models for the liquid phase can be encountered through the following publications: Thomas (1944), Chase (1984), Sarkar and Chattoraj (1993), Hamadi et al. (2001, 2004), Otero et al.(2004), Gulen et al.(2005) and Aroguz (2006). An important contribution comes from the work of Chase (1984), which implemented semi-analytical expressions to model the adsorption phenomenon in agitated tanks and chromatographic columns. He considered the kinetic concepts to model the adsorption process as a reversible system with an overall rate of second-order. In a general point of view, the above publications, with exception of the Chase model (Chase, 1984), use simplified or empiric expressions for the kinetic models. The advantage of utilizing the concepts of kinetic theory to develop new models is that the stoichiometric and order, related to the compounds in the adsorption system considered, can be varied and analyzed independently, leading to a better comprehension of the evolved kinetic phenomenology.

In this work an implemented kinetic model of adsorption is applied in the modeling of salicylic acid adsorption onto three different adsorbents, an activated carbon (F400) and two polymeric resins (F206 and F207), in three different temperature conditions. The model adjustment through the experimental data is done with the application of an inverse problem approach that minimize the square residues of a cost function.

\section{KINETIC MODELING}

The agitated adsorption techniques to measure adsorption parameters are modeled with the following expression for batch processes:

$$
r_{j}=\frac{1}{V} \frac{d n_{j}}{d t}
$$

in which $r_{j}$, that corresponds to the adsorption rate of component $j$, is proportional to the variation in the moles number of solute $j$. The tank volume $(V)$ is assumed constant.

The adsorption stoichiometry considered is represented in Fig. 1. It is related to an irreversible adsorption kinetic with a kinetic constant $k_{i}$. This adsorption mechanism depends both on the solute concentration (liquid phase) and the active surface concentration (site concentration in solid phase).

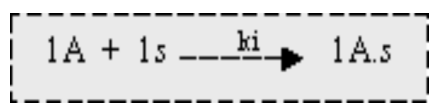

Figure 1. Representation of the adsorption mechanism.
The adsorption mechanism of Fig. 1 considers the adsorption of 1 (one) mol of solute $\mathrm{A}$ in 1 (one) mol of active site $(s)$. The kinetic modeling, in terms of consumption rate of solute $j\left(r_{j}\right)$, is written in the following form.

$$
\left(-r_{j}\right)=k_{i} C_{j}^{n} \cdot C_{s}^{m}
$$

Where $k_{i}, C_{j}$ and $C_{s}$ represent the kinetic constant, the concentration of solute $j$ in the liquid phase and the concentration of sites of adsorption in the solid phase, respectively. For a first order elementary adsorption, the exponents $\mathrm{n}$ and $\mathrm{m}$ are equal to 1 , which corresponds to an overall rate of second order. The irreversible adsorption is an adequate hypothesis, since in some experimental studies the desorption procedures are necessary to return the original adsorbent properties without solute traces (Pereira (1999), Silva (2000)). This is done with elution and washing steps.

With the considerations just described, Eq. (2) can be solved analytically through the expression (1), applying a balance in the moles number of active sites of adsorption, i.e.

$$
C_{t}=C_{s}+C_{A . S}
$$

in which $C_{t}$ corresponds to the maximum concentration of adsorption sites, that is the sum through the concentration of vacant sites $\left(C_{S}\right)$ and occupied sites by solute $\mathrm{A}\left(C_{A s}\right)$. Another important balance is related to the concentration of solute $A$. In the balance of solute $\mathrm{A}$, the initial concentration in the solution $\left(C_{A 0}\right)$ corresponds to the sum of the final solute concentration in the solution $\left(C_{A}\right)$ and the adsorbed solute concentration in the solid phase $\left(C_{A s}\right)$, i.e.

$$
C_{A 0}=C_{A}+C_{A . s}
$$

The Combination of Eqs.(1-4) leads to.

$$
\int \frac{d C_{A}}{C_{A}\left(a+C_{A}\right)}=\int-k_{i} d t
$$

in which $a=C_{t}-C_{A 0}$. Performing the integrations in Eq. (5) results.

$$
\ln \left(\frac{C_{A}}{a+C_{A}}\right)=-a \cdot k_{i} \cdot t+c
$$

We obtain the final expression of the irreversible adsorption kinetic model of overall order of 2 (IKM2) using the following boundary conditions.

$$
t=0 \Rightarrow\left\langle\begin{array}{l}
C_{A}=C_{A 0} \\
C_{t}=C_{s}
\end{array}, t=\infty \Rightarrow\left\langle\begin{array}{l}
C_{e q}=C_{A} \\
C_{t}=C_{A . s}
\end{array}\right.\right.
$$


The balance of the solute (Eq. 4) in the above conditions (Eq. 7) leads to the following form in the equilibrium.

$$
C_{A 0}=C_{t}+C_{e q}
$$

The equation below (Eq. 9) present the final expressions for the concentration of solute $\mathrm{A}$, with $C_{t}$ ,$C_{A 0}$ and $k_{i}$ in the time domain.

$$
C_{A}=\frac{a \cdot C_{A 0}}{\left(a+C_{A 0}\right) e^{-a \cdot k_{i} \cdot t}-C_{A 0}}
$$

Note that the implemented IKM2 expression comes from the moles balance following the moles relation shown in Fig. 1, which can be calculated independently of the volume of each phase. The parameter $a$ in the IKM2 (Eq. 9) can be substituted by the term $-C_{e q}$, becoming the model dependent on the liquid phase parameters.

The correlations with the kinetic model implemented in this work (IKM2) were obtained through the experimental data of Otero et al. (2004). The correlation results from the kinetic model applied by Otero et al. (2004) were also analyzed for comparison purposes.

In order to obtain estimates for the unknown parameters we formulate the inverse problem implicitly, as an optimization problem in which we look for the minimum value of the cost function. The last one is given by the summation of the squared residues between experimental $\left(C_{\text {exp }}\right)$ and calculated $\left(C_{c a l}\right)$ values of the solute concentration.

$$
Q=\sum_{i=1}^{N}\left(C_{\exp _{i}}-C_{c a l_{i}}\right)^{2}
$$

\section{RESULTS AND DISCUSSION}

The simulation results of IKM2 model are compared and correlated to three different adsorbent materials used in the adsorption of salicylic acid (Otero et al., 2004).

The simulation results were obtained assuming an equilibrium concentration $\left(C_{e q}\right)$ that corresponds to the final concentration of the solute in the solution. The equilibrium concentration is an important parameter in the adsorption process once it determines the concentration of adsorption sites (solid phase concentration) from a moles balance with the initial concentration of the solute (see Eq. 8). In all simulations were considered an implicit error in the equilibrium concentration $\left(C_{e q}\right)$. The $C_{e q}$ was varied in the range between -10 to $10 \%$ of its original value. It led to optimized simulation results with better fit between the model and the experimental data. This was confirmed by significant reductions in the cost function of squared residues $(Q)$.

The Figs. (2-4) present the correlation results between the IKM2 model and the experimental data from Otero et al. (2004). The results of solute concentration on the adsorbent phase $\left(q=C_{A s}\right)$ were plotted versus time. As can be observed from the Figs. (2-4), the IKM2 model showed high fit correlating the experimental points of all adsorbents in all temperature conditions.

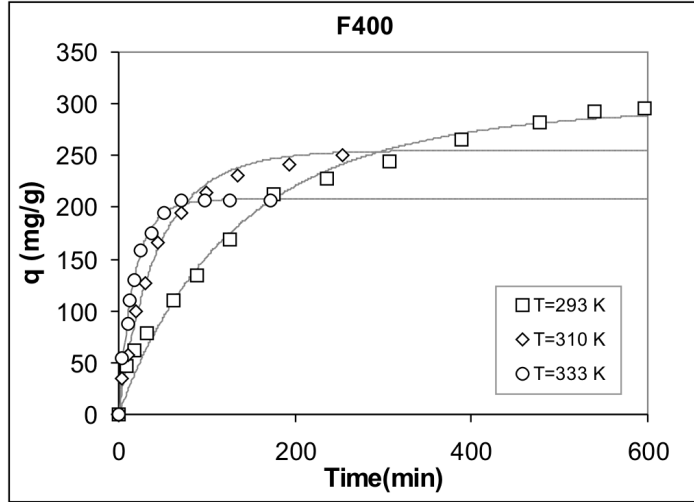

Figure 2. Correlation between the IKM2 model (lines) and the experimental data (points) for F400 adsorbent.

The IKM2 model was highly satisfactory correlating the experimental data both in the initial period of time and in long times. It provided better correlation results, according to best fits, than those obtained by Otero et al., 2004, which applied a linear driving force (LDF) model for the adsorption kinetic.

An interesting characteristic of the implemented model (IKM2) is the very small computational effort in obtaining the simulation results. It is related to the analytical form of the mathematical expression (Eq. 9). Besides the good agreement with the real experimental data, the kinetic model described (IKM2) requires only two parameters $\left(C_{A 0}\right.$ and $C_{t}$ or $\left.C_{e q}\right)$ to obtain the rate kinetic constants $\left(k_{i}\right)$.

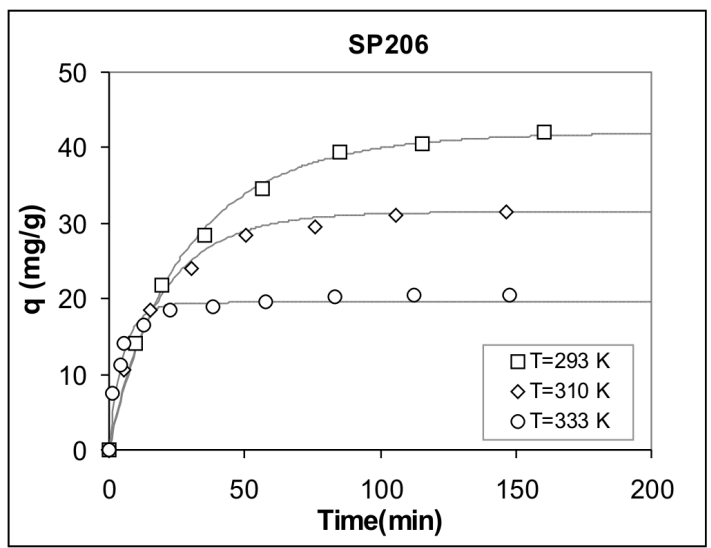

Figure 3. Correlation between the IKM2 model (lines) and the experimental data (points) for F206 adsorbent. 


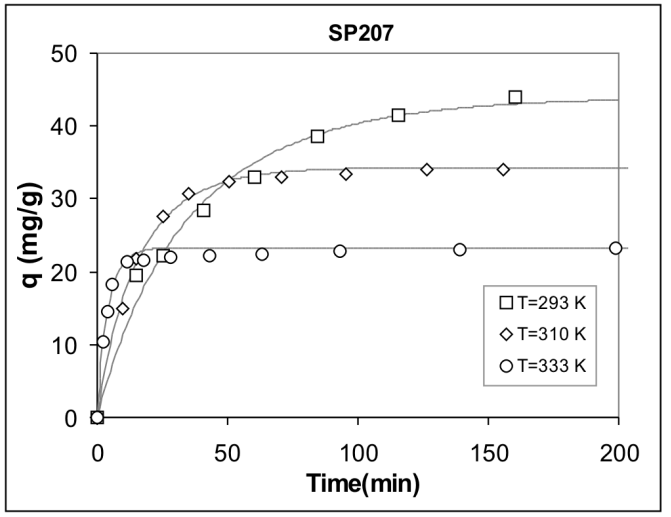

Figure 4. Correlation between the IKM2 model (lines) and the experimental data (points) for F207 adsorbent.

The Table 1 presents the kinetic constants of adsorption estimated from the IKM2 model. As can be seen from the Table 1, there is an increase in the kinetic constants with the increase in the temperature. This increase in the kinetic constant is accompanist by a reduction in the adsorption capacity of the adsorbent, as can be verified from the Figs. (2-4). The estimated kinetic constants from the polymeric adsorbents (F206 and F207) were greater than those from the activated carbon (F400), although the last one presented the high adsorption capacity (vide Fig. 2).

For the processes design, the optimization between retention capacity and adsorption rate (proportional to the kinetic constants) must be carried out to reach the desire temperature for the maximum production with the minimum time for the processing.

Table 1. Estimated kinetic constants of adsorption for each adsorbent.

\begin{tabular}{|c|c|c|c|}
\hline & \multicolumn{3}{|c|}{$\begin{array}{c}\text { Kinetic constants of adsorption } \\
(\mathrm{mL} / \mathrm{mg} . \mathrm{min})\end{array}$} \\
\hline Temp. (K) & F400 & F206 & F207 \\
\hline $293 \mathrm{~K}$ & 1.578 & 6.278 & 8.052 \\
\hline $310 \mathrm{~K}$ & 4.877 & 14.148 & 11.993 \\
\hline $333 \mathrm{~K}$ & 12.194 & 52.642 & 41.394 \\
\hline
\end{tabular}

Fig. 5 presents the behavior and the minimum of the cost function $(Q)$ by varying the kinetic constant $\left(k_{i}\right)$ for three different values of equilibrium concentration $\left(C_{e q}\right)$. These results correspond to the adsorption experiments through the adsorbent F400 in the temperature of $333 \mathrm{~K}$. The cases studied correspond to the $C_{e q}$ values of $76 \mathrm{mg} / \mathrm{L}, 83.1 \mathrm{mg} / \mathrm{L}$ and $79.2 \mathrm{mg} / \mathrm{L}$. The first and second one correspond to the values obtained by Otero et al. (2004), from the Langmuir model correlation and the equilibrium kinetic experiments, respectively. The last one was obtained from the optimization procedure of $C_{e q}$ (varied in the range of -10 to $10 \%$ of its original). As can be seen, the minimum cost function presented smooth profiles that led to absolute minimums in some determined kinetic constants values. The optimized condition $\left(C_{e q}=79.2 \mathrm{mg} / \mathrm{L}\right)$ showed the great absolute minimum. The $C_{e q}$ cases from the Langmuir isotherm and the equilibrium kinetic experiments presented the high residue value if compared to the optimized condition. The last procedure can leads to erroneous estimation of parameters.

The results of the Fig. 5 showed that an improvement in the model correlation with experimental data can be obtained, what is related to the reduction in the cost function. It was reached optimizing the equilibrium concentration in a predetermined range of error.

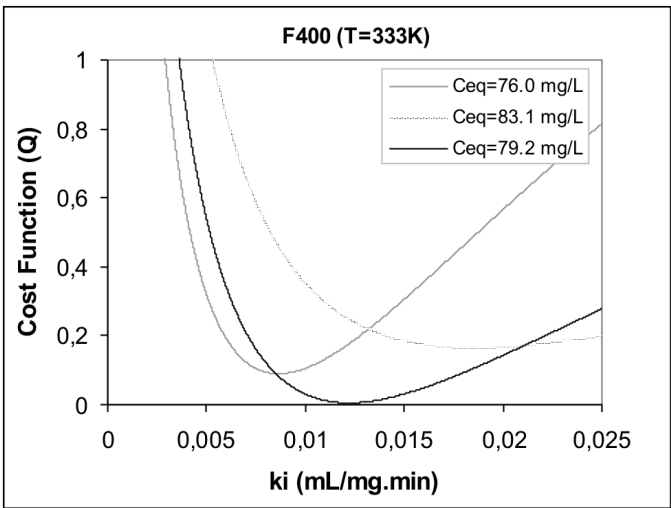

Figure 5. Residues of the cost function $(Q)$ for three equilibrium concentrations.

The estimated kinetic constants (Table 1) were applied into the Ahrrenius equation (Eq. 11), making possible the determination of the adsorption activation energies for the adsorbents studied.

$$
k_{i}=A \cdot e^{-\frac{E_{a}}{R \cdot T}}
$$

where $A, E_{a}$ and $T$ represents the frequency factor $\left(\mathrm{min}^{-1}\right)$, The activation energy $(\mathrm{J} / \mathrm{mol})$ and the temperature $(\mathrm{K})$, respectively, utilizing the constant $R$ equals to $8.314 \mathrm{~J} / \mathrm{mol} . \mathrm{K}$. The application of logarithmic in both equation sides becomes the Ahrrenius equation linear. The results are plotted in the Fig. 6. The activation energy comes from the angular term of the straight equation. 


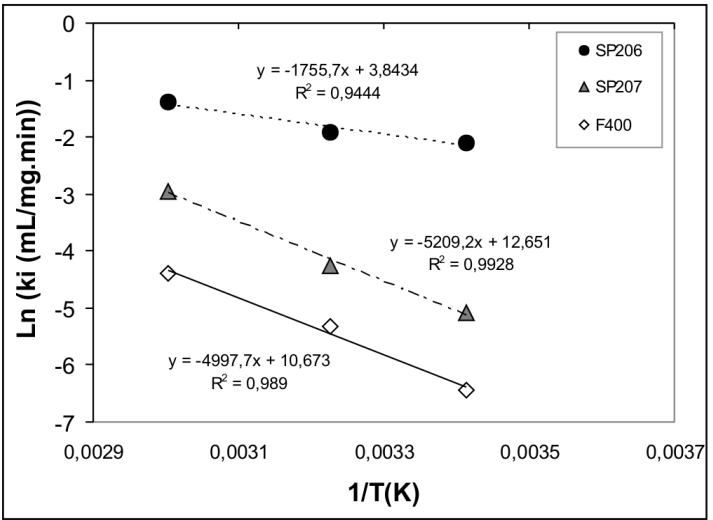

Figure 6. Linear form of the Ahrrenius equation for the determination of the adsorption activation energy.

Other thermodynamics parameters were determined through the expression of the free energy of Gibbs $(\Delta G)$,

$$
\Delta G=\Delta H-T . \Delta S
$$

in which $\Delta H, \Delta S$ and $T$ correspond to the variation of enthalpy and entropy and the temperature, respectively. The free energy of Gibbs, in the standard state $\left(\Delta G^{0}\right)$, is represented by the Eq. (13).

$$
\Delta G^{o}=-R \cdot T \cdot \operatorname{Ln}\left(K_{c}\right)
$$

The term $K_{c}$ represents the equilibrium constant. It is obtained through the ratio of the solid phase and the liquid phase concentration in the equilibrium (Aroguz, 2006). The Eqs. (12) and (13) combined lead to the linear form of the Eq. (14).

$$
\operatorname{Ln}\left(K_{c}\right)=-\left(\frac{\Delta H^{o}}{R \cdot T}\right)+\left(\frac{\Delta S^{o}}{R}\right)
$$

The parameters $\Delta S_{0}$ and $\Delta H_{0}$ were obtained, respectively, from the linear and angular coefficient of the Eq. (14). The thermodynamics parameters, from Eqs. (11) and (14) are presented in the Table 2.

Table 2. Estimated kinetic constants of adsorption for each adsorbent.

\begin{tabular}{|c|c|c|c|}
\hline & $\mathrm{F} 400$ & $\mathrm{~F} 206$ & $\mathrm{~F} 207$ \\
\hline $\begin{array}{c}E_{a} \\
(\mathrm{KJ} / \mathrm{mol})\end{array}$ & 41.55 & 14.6 & 43.31 \\
\hline $\begin{array}{c}\Delta H^{0} \\
(\mathrm{KJ} / \mathrm{mol})\end{array}$ & -9.75 & -21.31 & -17.34 \\
\hline $\begin{array}{c}\Delta S^{0} \\
(\mathrm{~J} / \mathrm{mol})\end{array}$ & -40.44 & -77.9 & -65.24 \\
\hline
\end{tabular}

Analyzing the data of Table 2 can be verified values of activation energies that correspond to mechanisms of physisorption (Aroguz, 2006). These values are in the high limit of physisorption, in which after it there is the chemisorption domain. The negative variation of enthalpy and entropy is related to the adsorption that is exothermic and to the decrease in the system disorder, respectively. An increase in the temperature leads to a decrease in the equilibrium constant, as the adsorption process is exothermic. This is verified from the Figs 2-4, in which the retention capacity decrease with the increase in the temperature. So, the adsorption is not spontaneous with the increase in the temperature.

\section{CONCLUSIONS}

The analytical kinetic model of adsorption implemented (IKM2) has proved to be satisfactory due to a number of aspects. Firstly, it provided better agreements with experimental data when compared to other kinetic models, such as the kinetic model of linear driving force (Otero et al., 2004). Other relevant aspects are related to the necessity of a small number of parameters in the model and the straightforward procedure obtaining the solution. It turned out to be very useful when associated to the square residues inverse modeling.

The consideration of an acceptable error domain for the equilibrium concentration $\left(C_{e q}\right)$ provided good results by reductions in the residues cost function, which led to a better experimental correlation with an increase in the accuracy of the parameters estimated. In the procedures evolved with the correlation of experimental equilibrium data with isotherm models, such as Langmuir model, a special treatment must be considered since implicit errors can lead to erroneous estimation of parameters.

The simulated results indicated an increase in the kinetic parameters $\left(k_{i}\right)$ with an increase in the temperature for all the adsorbents studied. The increase in the kinetic constants or adsorption velocity was followed by a reduction in the retention capacity of the solid phase. It was confirmed by the thermodynamic parameters obtained.

The observed decrease in the capacity of adsorbent with the increase in the temperature must be analyzed and optimized in terms of adsorption velocity (related to the kinetic constants) as the last one decrease the time for the processing.

\section{ACKNOWLEDGEMENTS}

The authors acknowledgment the financial support provided by CNPq (Conselho Nacional de Desenvolvimento Científico e Regional), FAPERJ (Fundação Carlos Chagas Filho de Amparo à Pesquisa do Estado do Rio de Janeiro) and CAPES/CGCI (Coordenação de Aperfeiçoamento de Pessoal de Nível Superior- Coordenação Geral de Cooperação Internacional). 


\section{REFERENCES}

Aroguz, A. Z., 2006, Kinetics and Thermodynamics of Adsorption of Azinphosmethyl from Aqueous Solution onto Pyrolyzed (at $600^{\circ} \mathrm{C}$ ) Ocean Peat Moss (Sphagnum sp.), Journal of Hazardous Materials, Vol. 135, No. 1-3, pp. 100-105.

Chase, H. A., 1984, Prediction of the Performance of Preparative Affinity Chromatography, J. Chromatography, Vol. 297, pp. 179-202.

Denisov, A. M., 2000, Inverse Problems of Absorption Dynamics, Proc. Minisymposium on Inverse Problems in Medicine, Engineering and Geophysics-Proc. XXIII Brazilian Congress on Applied and Computational Mathematics, SantosBrazil, pp. 24-32. (Invited Lecture)

Felinger, A., Zhou, D. and Guiochon, G., 2003, Determination of the Single Component and Competitive Adsorption Isotherms of the 1-Indanol Enantiomers by Inverse Method, Journal of Chromatography A, Vol. 1005, pp. 35-49.

Folly, F. M., Silva Neto, A. J. and Santana, C. C., 2005, An Inverse Mass Transfer Problem for the Characterization of Simulated Moving Bed Adsorption Columns, Proceedings 5th Intern. Conf. on Inverse Problems in Eng, Cambridge, UK, 11-15th July.

Gulen, J., Aroguz, A. Z.and Dalgin, D., 2005, Adsorption Kinetics of Azinphosmethyl from Aqueous Solution onto Pyrolyzed Horseshoe Sea Crab Shell from the Atlantic Ocean, Bioresource Technology, Vol. 96, pp. 1169-1174.

Hamadi, N. K., Chen, X. D., Farid, M. M. and Lu, M. G. Q., 2001, Adsorption Kinetics for the Removal of Chromium(VI) from Aqueous Solution by Adsorbents Derived from Used Tires and Sawdust, Chemical Engineering Journal, Vol. 84, pp. 95-105.

Hamadi, N. K., Swaminathan, S. and Chen, X. D., 2004, Adsorption of Paraquat Dichloride From Aqueous Solution by Activated Carbon Derived from Used Tires, Journal of Hazardous Materials B, Vol. 112, pp. 133-141.

Lugon Jr, J., Silva Neto, A. J. and Santana, C. C., 2001, An Inverse Mass Transfer Problem in GasLiquid Adsorption in Columns of Bubble and Foam, Inverse Problems in Engineering Symposium, College Station, Texas, EUA.

Otero, M., Grande, C. A. and Rodrigues, A. E., 2004, Adsorption of Salicylic Acid onto Polymeric
Adsorbents and Activated Charcoal, Reactive and Functional Polymers, Vol. 60, pp. 203-213.

Pereira, J. A. M., 1999, Adsorption of $\beta$ Galactosidase from Scopulariopsis $\mathrm{sp}$ in Ion Exchange Resin with Purification and Scaling-up objective, D.Sc. Thesis, Universidade Estadual de Campinas, São Paulo, Brazil. (In Portuguese)

Sarkar, D. and Chattoraj, D. K., 1993, Activation Parameters for Kinetics of Protein Adsorption at Silica-Water Interface, Journal of Colloid and Interface Science, Vol. 157, pp. 219-226.

Silva, F. R. C., 2000, Study of Inulinases Adsorption in Columns with Ion Exchange Resin: Experimental Parameters and Modeling, D.Sc. Thesis, Universidade Estadual de Campinas, São Paulo, Brazil. (In Portuguese)

Thomas, H., 1944, "Heterogeneous Ion Exchange in Flowing System", J. Am. Chem. Soc., Vol. 66, pp. 1664-1668.

Vasconcellos, J. F. V., Silva Neto, A. J., Soeiro, F. J. P. and Santana, C. C., 2002a, Parameter Estimation in Adsorption Columns with a Stochastic Global Method, Proc. 4th Internat. Conf. on Inverse Problems. Rio de Janeiro, Brazil.

Vasconcellos, J. F. V., Silva Neto, A. J. and Santana, C. C., 2002b, An Inverse Mass Transfer Problem of Parameter Estimation in Adsorption Columns, Proc. 5th World Congress on Computational Mechanics. Vienna, Austria.

Vasconcellos, J .F. V., Silva Neto, A. J. and Santana, C. C., 2003 An Inverse Mass Transfer Problem in Solid-Liquid Adsorption Systems, Inverse Problems in Eng., Vol. 11, No. 5, pp. 391-408. 